11. A Wagner-Meerwein rearrangement in the cationic moiety of 11 involving migration of the bicyclobutane bridgehead carbon atom trans to the anionic moiety ${ }^{[3]}$ would then have to occur to give 12 , which would subsequently yield 8 .

In contrast to the reaction with 1,4-benzoquinone, irradiation $^{[4]}$ of $1^{[5]}$ with 1,4-naphthoquinone $\left(E_{\mathrm{T}}=57 \mathrm{kcal}\right.$ $\left.\mathrm{mol}^{-1[6 \mathrm{c}]}\right)$ at $-30^{\circ} \mathrm{C}$ gave the cyclobutane $13^{[7]}(17 \%)$. Motivated by the work of Cantrell, ${ }^{[11]}$ we also employed 2-benzoylthiophene $\left(62.6 \mathrm{kcal} \mathrm{mol}^{-1[11 \mathrm{~J}}\right)$ at room temperature as well as 2-acetylthiophene $\left(64.5 \mathrm{kcal} \mathrm{mol}^{-1[11]}\right)$ and 2-acetylfuran $\left(64.9 \mathrm{kcal} \mathrm{mol}^{-1[1]}\right)$ at $-30^{\circ} \mathrm{C}$ and obtained the $[2+2]$ cycloadducts $14(21 \%)$, and $15(27 \%)$ as well as the $[4+2]$ cycloadduct $16(19 \%)$ together with its diastereomer $(6 \%){ }^{[7]} \mathrm{At}-30^{\circ} \mathrm{C}$, excited 1 -acetylnaphthalene $(56.4 \mathrm{kcal}$ $\mathrm{mol}^{\left.-1{ }^{16 \mathrm{al}}\right)}$ and $1^{[5]}$ gave initially the [4 +2$]$ cycloadduct 17 $(25 \%)$. Upon further irradiation, however, 17 was converted at a similar rate into $18(41 \%)$ and $19(9 \%)^{[7]}$ (di- $\pi$-methane rearrangement). Selected physical data for 13-19 are given in Table 1.

We obtained no cycloadduct from 1 and cyclopent-2-en-1one $\left(E_{\mathrm{r}}=74 \mathrm{kcal} \mathrm{mol}^{-1[2 \mathrm{a}]}\right)$. In conclusion, 1 , too, can undergo photochemical cycloadditions, provided that the reaction partner has a triplet energy $E_{\mathrm{T}}<65 \mathrm{kcal} \mathrm{mol}^{-1}$.

Received: December 7, 1988 [Z 3078 IE] German version: Angew. Chem. 101 (1989) 636

CAS Registry numbers: $1,659-85-8 ; 2,120229-54-1 ; 3$ isomer $1,120229-55-2$; 3 isomer $2,120328-37-2 ; 4,120229-56-3 ; 5,120229-57-4 ; 6,120229-58-5 ; 7$, $120262-48-8 ; 8,120229-59-6 ; 13,120229-60-9 ; 14,120229-61-0 ; 15,120229-62-$ 1 ; 16 isomer $1,120229-63-2 ; 16$ isomer $2,120328-38-3 ; 17,120229-64-3 ; 18$, $120262-49-9 ; 19,120220-65-4 ;\left(\mathrm{MeCO}_{2}, 431-03-8 ;\left(\mathrm{PhCO}_{2}, 134-81-6\right.\right.$; methylphenylglyoxylate, $15206-55-0 ; 1,4$-benzoquinone, 106-51-4; chloranil 118-75-2, 1,4-naphthoquinone, 130-15-4; 2-benzoylthiophene, 135-00-2; 2 acetylthiophene, 88-15-3; 2-acetylfuran, 1192-62-7; 1-acetylnaphthalene, 94198-0.

[1] C. A. Renner, T. J. Katz, J. Pouliquen, N. J. Turro, W. H. Waddell, J. Am Chem. Soc. 97 (1975) 2568

[2] a) N. J. Turro: Modern Molecular Photochemistry, Benjamin/Cummings, Menlo Park, 1978; b) W. M. Horspool (Ed.): Synthetic Organic Photochemistry, Plenum Press, New York 1984.

[3] a) M. Christl, Angew. Chem. 93 (1981) 515; Angew. Chem. Int. Ed. Engl. 20 (1981) 529, and references cited therein; b) M. Christl, E. Brunn, F. Lanzendörfer, J. Am. Chem. Soc. 106 (1984) 373.

[4] Light sources: medium-pressure $\mathrm{Hg}$ lamp (Hanovia, 450 W) in a Pyrex immersion well; radiation with $\lambda<400 \mathrm{~nm}$ was filtered out for colored substrates. 1,4-Naphthoquinone and 1-acetylnaphthalene were irradiated in a Rayonet ${ }^{\text {RPR }} 100$ photoreactor with $350-\mathrm{nm}$ and $300-\mathrm{nm}$ light, respectively.

[5] We used 1 as a solution in hexane, which was diluted with the same or up to a fivefold quantity of benzene (experiments at room temperature) or toluene (experiments at $-30^{\circ} \mathrm{C}$ ). The solutions, which were saturated with nitrogen before photolysis, were ca. $0.10 \mathrm{M}$ in 1 and $0.05 \mathrm{M}$ in the carbonyl compound.

[6] a) W. G. Herkstroeter, A. A. Lamola, G. S. Hammond, J. Am. Chem. Soc. 86 (1964) 4537; b) P. Longin, A.-M. Lambert, M. A. Rousset, C.R. Acad. Sci. Ser. B 273 (1971) 599; c) G. S. Hammond, J. Saltiel, A. A. Lamola, N. J. Turro, J. S. Bradshaw, D. O. Cowan, R. C. Counsell, V. Vogt, C. Dalton, J. Am. Chem. Soc. 86 (1964) 3197.

[7] The isolation was carried out by flash chromatography with petroleum ether/ethyl acetate on $\mathrm{SiO}_{2}(4-8,13-15)$ or on basic $\mathrm{Al}_{2} \mathrm{O}_{3}$, activity III $(17-19)$, and by preparative gas chromatography with Carbowax $20 \mathrm{M}$ on Volaspher $^{\mathrm{R}}$ A $2(2,3)$ or silicon SE 30 on Chromosorb ${ }^{30} \mathrm{~W}$ (16 and diastereomer). Elemental analyses as well as mass, IR, and NMR spectra support the proposed structures. Except for 13, the configurations were determined from the characteristic magnitudes of the coupling constants or from NOE effects

[8] Analysis by ${ }^{2} \mathrm{H}$ NMR spectroscopy.

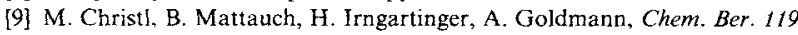
(1986) 950

(101 a) J. Mattay, Angew. Chem. 99 (1987) 849; Angew. Chem. Int. Ed. Engl. 26 (1987) 825 ; b) C. J. Abelt, H. D. Roth, M. L.M. Schilling, J. Am. Chem. Soc. 107 (1985) 4148 .

[11] T. S. Cantrell, J. Org. Chem. 39 (1974) 2242

\section{Synthesis and Structure of Digerma- and Distannacyclobutenes **}

\section{By Adolf Krebs, * Andrea Jacobsen-Bauer, Erhard Haupt, Michael Veith, ${ }^{*}$ and Volker Huch}

The first germirenes (germacyclopropenes) were synthesized by reaction of 3,3,6,6-tetramethyl-1-thiacyclohept-4yne 1 with suitable precursors of dialkylgermylenes (dialkylgermanediyls); ${ }^{[1]} 1$ combines high reactivity of the $\mathrm{C}-\mathrm{C}$ triple bond with steric shielding of the resulting addition product, thereby often making possible the synthesis of systems otherwise accessible only with difficulty. ${ }^{[2]}$ Since, until recently, no addition reactions of stannylenes to $\mathrm{C}-\mathrm{C}$ triple bonds had been described, ${ }^{[3]}$ we allowed 1 to react with the stabilized diaminogermylene $2^{[4]}$ as well as the diaminostannylene $3^{[4]}$ and obtained, in addition to the digermacyclobutene 4 , the first distannacyclobutene 5 . Compounds 4 and 5 are both dispiro compounds.

Addition of 1 to the red solution of 3 in various solvents (benzene, THF, $n$-hexane, diethyl ether) resulted in immediate precipitation of a yellow solid, whose ${ }^{1} \mathrm{H}$ and ${ }^{13} \mathrm{C}$ NMR spectroscopic data in concentrated solution indicate the formation of the $1: 2$ adduct 5 . In dilute solution, however, only the ${ }^{1} \mathrm{H}$ NMR signals of the starting materials were observed; in the ${ }^{13} \mathrm{C}$ NMR spectrum of 5 , the signal for the sp-hybridized $\mathrm{C}$ atom of 1 was absent. Proof for the presence of an $\mathrm{Sn}-\mathrm{Sn}$ bond was provided by the ${ }^{119} \mathrm{Sn}$ NMR spectrum, which showed a signal at $\delta=+155$ (rel. to $\mathrm{Sn}\left(\mathrm{CH}_{3}\right)_{4}$; $\left.J\left({ }^{119} \mathrm{Sn},{ }^{117} \mathrm{Sn}\right)=3723 \mathrm{~Hz}\right)$. Compound 4 was synthesized in a similar way from 1 and 2.
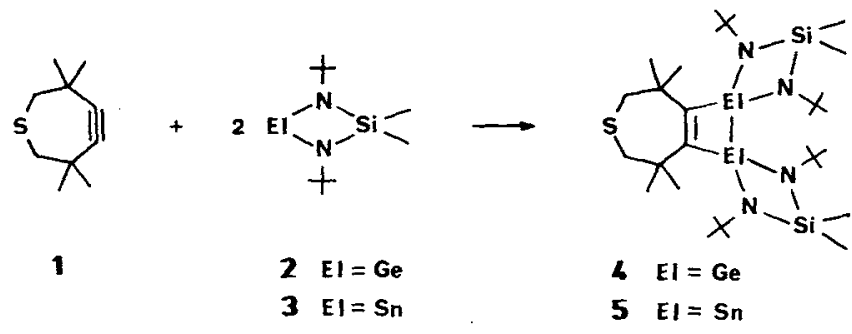

The results of the X-ray structure analyses of 4 and 5 are given in Figure 1. They confirm the structure derived for 5 in solution. In both cases, there is a central four-membered ring containing two $\mathrm{sp}^{2}$-hybridized carbon atoms and two fourfold coordinated germanium or tin atoms, respectively. Whereas in $\mathbf{5}$ the nearly planar peripheral diazasilastanna four-membered rings are perpendicular to the completely planar central distannacyclobutene ( 5 has a $C_{2}$ axis in the crystal, the thiacycloheptene unit being disordered; only one of the two variants is shown in Fig. 1), the diazasilagerma four-membered rings in 4 , which are also planar, are twisted

[*] Prof. Dr. A. Krebs, Dipl-Chem. A. Jacobsen-Bauer Institut für Organische Chemie der Universität Martin-Luther-King-Platz 6, D-2000 Hamburg 13 (FRG) Dr. E. Haupt

Institut für Anorganische und Angewandte Chemie der Universität Hamburg

Prof. Dr. M. Veith, Dr. V. Huch Institut für Anorganische Chemie der Universität Im Stadtwald, D-6600 Saarbrücken 11 (FRG)

[**] Cyclic Diazastannylenes, Part 29. Part 28: M. Veith, V. Huch, R. Lisowsky, P. Hobein, Z. Anorg. Allg. Chem., in press. 

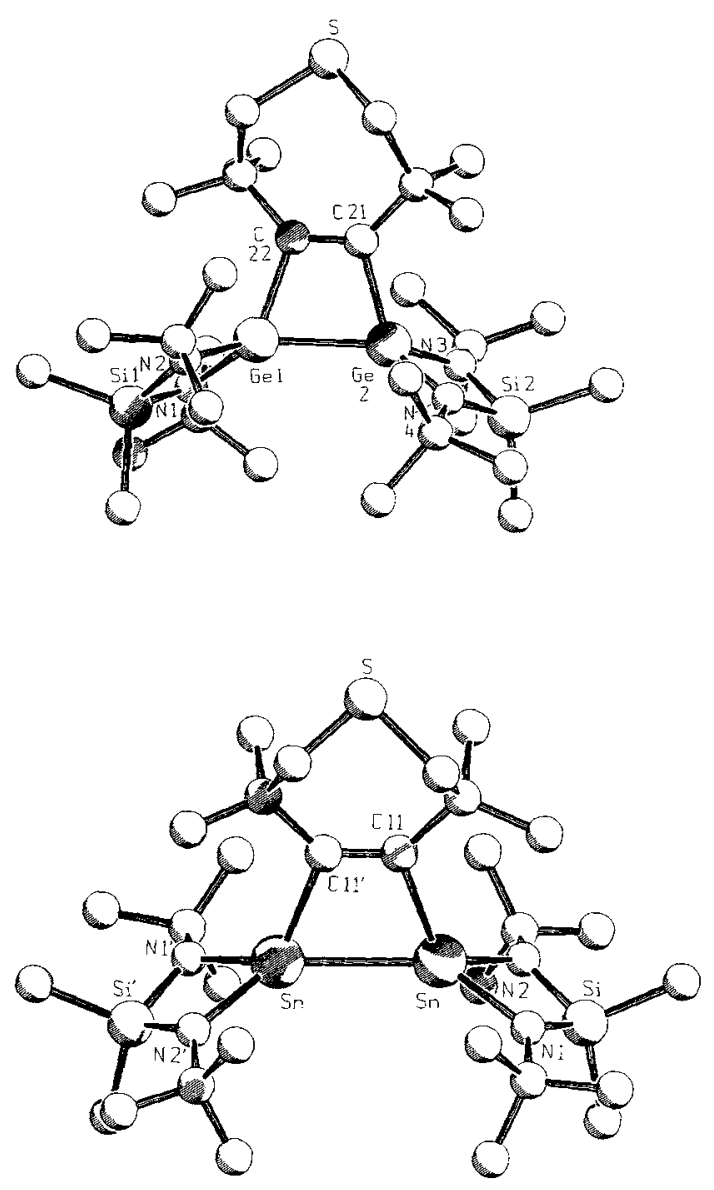

Fig. 1. Molecular structures of 4 (top) and 5 (bottom). Important bond lengths $[\AA]$ and angles $\left[^{0}\right]^{[5]}$ in the dimetallacyclobutenes: 4: Ge1-Ge2 2.459(1). Ge1C22 2.030 (7), Ge2-C21 2.028 (6), C21-C22 = 1.34 (1); C22-Ge1-Ge2 73.3(1), Ge2-C21-C22 105.0 (1). 5: Sn-Sn' 2.803 (1), Sn-C11 2.27 (1), C11-C11'1.31 (2); C11-Sn-Sn' 70.7 (2), Sn-C11-C11' 109.3 (3) [5].

away from orthogonal positions with respect to the slightly puckered digermacyclobutene. This twisting is due to the sterically demanding tert-butyl groups on the nitrogen atoms of the two peripheral rings. Compound 5 is not twisted because the $\mathrm{Sn}-\mathrm{Sn}$ distance is $0.344 \AA$ longer, thereby reducing this steric interaction.

Whereas the bond lengths and angles of the central ring of 4 are in the expected range, the $\mathrm{C}=\mathrm{C}$ bond in 5 is quite short $(1.31 \AA$ versus the expected value of $1.34 \AA)$ and the $\mathrm{Sn}-\mathrm{C}$ bonds are very long $(2.27 \AA$ versus the expected value of $2.17 \AA)$. ${ }^{61}$ For comparison, in the stannirene synthesized by Sita et al., ${ }^{[3]}$ the bond lengths are $d(\mathrm{C}=\mathrm{C})=1.34 \AA$ and $d(\mathrm{Sn}-\mathrm{C})=2.14 \AA$. The $\mathrm{Sn}-\mathrm{C}$ bond is thus very weak, which would also explain the dissociation to the starting compounds observed in solution.

Compound 5 could have formed either via the stannirene 6 and subsequent insertion of 3 or by a $[2+2]$ cycloaddition

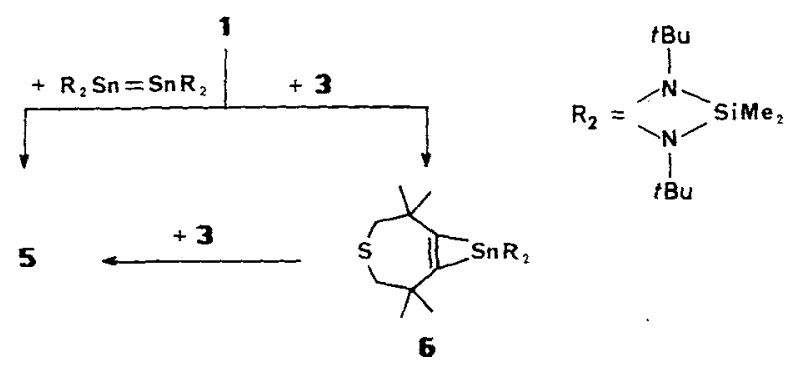

of 1 and a dimer of 3 having an $\mathrm{Sn}-\mathrm{Sn}$ double bond; since such dimers of 3 are not known ${ }^{[7]}$ whereas a stannirene has already been isolated, ${ }^{[3]}$ we believe that the pathway via 6 is more likely. Both pathways to the 1,2-digermacyclobutene are possible in the case of the dialkylgermylenes. ${ }^{[8]}$ Phosphadistannacyclobutenes, however, are probably formed by $[2+2]$ cycloaddition. ${ }^{[9]}$

\section{Experimental Procedure}

4, 5: Compound $1(0.78 \mathrm{~g}, 4.68 \mathrm{mmol})$ was added dropwise under argon to 2 $(1.28 \mathrm{~g}, 4.68 \mathrm{mmol})$ or $3(1.5 \mathrm{~g}, 4.68 \mathrm{mmol})$ in $5 \mathrm{~mL}$ of dry benzene at $+10^{\circ} \mathrm{C}$ over $5 \mathrm{~min}$, resulting in the formation of yellow crystals. After parification $(4$. recrystallization from benzene; 5 , sublimation at $40-50^{\circ} \mathrm{C} / 10^{-3}$ torr), $1.43 \mathrm{~g}$ of $4(86 \%)$ or $1.05 \mathrm{~g}$ of $5(56 \%)$ was obtained.

Received: October 21, 1988 [Z. 3020 [E]

German version: Angew: Chem. 101 (1989) 640

CAS Registry numbers: $1,26825-18-3 ; 2,84806-15-5 ; 3,54724-62-8 ; 4,119787$. $85-8 ; 5,119793-90-7$.

[1] A. Krebs, J. Berndt, Tetrahedron Lett, 24 (1983) 4083; M. P. Egorov, S. P. Kolesnikov, Yu. T. Struchkov, M. Yu. Antipin, S. V. Sereda, O. M. Nefedov, J. Organomet. Chem. 290 (1985) C 27.

[2] A. Krebs, J. Wilke, Top. Curr. Chem. 109 (1983) 189.

[3] L. R. Sita, R. D. Bickerstaff, J. Am. Chem. Soc. $110(1988) 5208$.

[4] M. Veith, M. Grosser, Z. Naturforsch. B37 (1982) 1375; M. Veith, Angew. Chem. 87 (1975) 287; Angew. Chem. Int. Ed. Engl. 14 (1975) 263.

[5] 4: $C_{30} \mathrm{H}_{64} \mathrm{~N}_{4} \mathrm{SSi}_{2} \mathrm{Ge}_{2}$, space group $P 2, n, a=10.761(9), b=31.85$ (3), $c=12.54 \quad(1) \AA, \quad \beta=114.61 \quad$ (7) $\%, \quad V=3908 \AA^{3}, \quad Z=4, \quad \varrho_{\text {calcd. }}=$ $1.197 \mathrm{~g} \mathrm{~cm}^{-3}, \mu\left(\mathrm{Mo}_{\mathrm{K} \alpha}\right)=16.25 \mathrm{~cm}^{-1} .4634$ unique reflections, 1047 classified as not observed $(F \leq 3 \sigma(F))$. Reflection/parameter ratio $=15$. $R=0.057 .-5: \mathrm{C}_{30} \mathrm{H}_{64} \mathrm{~N}_{4} \mathrm{SSi}_{2} \mathrm{Sn}_{2}$, space group $C 2, a=17.135(9), b=$ $10.223(5), \quad c=14.233 \quad(7) \AA, \quad \beta=125.63 \quad(4)^{\circ}, \quad V=2026 \AA^{3}, Z=2$, $Q_{\text {culcd }}=1.305 \mathrm{gcm}^{-3}, \mu\left(\mathrm{Mo}_{\mathrm{K} \alpha}=12.52 \mathrm{~cm}^{-1} .1410\right.$ unique reflections, 14 classified as not observed $(F \leq 3 \sigma(F)$ ). Reflection/parameter ratio $=8.2$. $R=0.044,-F u r t h e r$ details of the crystal structure investigations may be obtained from the Fachinformationszentrum Energie, Physik, Mathematik GmbH, D-7514 Eggenstein-Leopoldshafen 2(FRG), on quoting the depository number CSD-53454, the names of the authors, and the journal citation.

[6] M. Veith, O. Recktenwald, Top. Curr. Chem. 104 (1982) 1.

[7] M. Veith, Angew. Chem. 99 (1987) 1; Angew. Chem. Int. Ed. Engl. 26 (1987) 1

[8] O. M. Nefedov, M. P. Egorov, A. M. Gal'minas, S.P. Kolesnikov, A. Krebs, J. Berndt, J. Organomet. Chem. 301 (1986) C 21

[9] A. H. Cowley, S. W. Hall, C. M. Nunn, J. M. Power, Angen: Chem, 100 (1988) 874; Angew. Chem. Int. Ed. Engl. 27 (1988) 838.

\section{Highly Reduced Porphyrins**}

\section{By Robert Cosmo, Christian Kautz, Klaus Meerholz, Jürgen Heinze, * und Klaus Müllen*}

Can an organic $\pi$ system be used to store charge by successive addition of electrons and is the storage capacity increased on going to higher analogues containing several redox centers? We have examined this question for the first time for porphyrins ${ }^{[1]}$ and have found that the zinc complex 1 of meso-tetratolylporphyrin 2 can reversibly accept six electrons. The NMR spectra of the intermediate di- and tetra-

[*] Prof. Dr. K. Müllen. Dr. R. Cosmo, Dipl.-Chem. C. Kautz Institut für Organische Chemie der Universität J.-J.-Becher-Weg 18 - 22, D-6500 Mainz 1 (FRG)

Prof. Dr. J. Heinze, Dipl.-Chem. K. Meerholz Institut für Physikalische Chemie der Universität Albert-Strasse 21, D-7800 Freiburg (FRG)

$\left[{ }^{* *}\right]$ This work was supported by the Deutsche Forschungsgemeinschaft and the Fonds der Chemischen Industrie. R.C. thanks the Alexander von Humboldt Foundation for a fellowship. 